\title{
Failed Histories of Electronic Music
}

\author{
DANIEL R. WILSON \\ c/o Resonance 104.4FM, 144 Borough High Street, London, SE1 1LB \\ Email: ashfordaisyak@googlemail.com
}

\begin{abstract}
This article counters the canonical histories of electronic music that traditionally begin with Cahill's Telharmonium and find their historical centre in the activities of the Paris and Cologne studios of the mid-twentieth century. The concept of 'failed histories' is introduced here with three important examples. The first chronicles the career of electromusical innovator Johann Baptist Schalkenbach (1824-1910). The second example examines Britain's earliest electronic sound performance in 1895 , signalling a rupture between electromusical bombast and the detailed, quiet work of the experimental laboratory. The third episode looks at the wireless oscillation outrages of the 1920s and 1930s, where electronic tone prematurely trespassed upon musical culture. Taken together, these failed histories offer an alternative narrative of electronic music finding its voice (and losing its voice) in turn-of-the-century Britain.
\end{abstract}

\section{INTRODUCTION}

In 1991 the physicist Robert Schumacher fleetingly mentioned the term 'failed subharmonics' in a paper on improving the realism of sound synthesis (Figure 1). Schumacher saw such aperiodicities (i.e. non-periodic events) as the near-unsynthesisable touchstone of realism (Schumacher 1991). It is a term that may be analogised here with failed histories that, unlike established histories, are never periodically rehashed, existing only as singular 'spikes' in time. It would appear that, depending on cultural conditions, some material is impervious to uptake into historical continua. Like failed subharmonics, failed histories are as much determined by their own character as by the conditions of the continua they seek to adhere to.

\section{MODUS OPERANDI}

Presented here are three neglected episodes that constitute failed histories. Each of these episodes came to light through an approach to research distinct from that of high academia, initiated by offbeat primary source material found during bin-diving, house clearances, car boot sales and auction-houses - venues at culture's tail-end. The episodes later formed the cores of my numerous failed applications for $\mathrm{PhD}$ funding over the years, and it was in the light of this that the concept of failed histories was crystallised.
The subjects of some failed histories were popular in their day, so the determinant factors that arrested their chances of sustaining a presence in later discourses can be attributed to subsequent cultural shifts that halted any regularity of citation.

Two of the following episodes are entirely absent from electronic music discourse. This first episode is not completely absent, but its significance has not been recognised. The disparity in length between the sections reflects the amount of primary source material obtainable for each episode.

\section{THE BIRTH OF AN ELECTRICAL MUSIC AESTHETIC}

Johann Baptist Schalkenbach (1824-1910) was a Prussian-born inventor, musician, performer and acoustician who developed the concept of combining electricity and music (Wilson 2013). His photographic portrait appears among others in the 1911 Era Annual's 'Deaths of the Year', a distinction reserved for the most prominent deceased artistes of the day.

For such a renowned figure it is striking to discover that later references to Schalkenbach are few and far between. A reminiscence by music hall agent Hugh Jay Didcott [aka Maurice Joseph] (1841-1909) formed a preface to a 1908 book of published performer salaries. He mused: 'Schalkenbach is forgotten, I suppose. He was the first man to produce mysterious music all over the place from a keyboard on the stage' (Weldon 1908). In 1921, William Bailey (1845-1927) recalled his duties introducing Schalkenbach at London's Canterbury Music Hall in 1873 (The Performer 3 November 1921). In 1967, magic historian George Jenness (1901-88) published his study of Maskelyne and Cooke's Egyptian Hall residency where Schalkenbach appeared with his Orchestre Militaire Electro Moteur. Jenness wrote: 'whatever this may have been, we are told [...] there were beautiful and marvellous musical effects by electricity' (Jenness 1967). An 1863 engraving (Figure 2) of Schalkenbach's instrument was reproduced in James R. Gaines's 1981 book The Lives of the Piano where it is briefly (and erroneously) referred to as a 'bizarre' piano modification (Gaines 1981). 
In more recent years, Schalkenbach's stint at the Royal Polytechnic Institution was touched upon in Jeremy Brooker's 2005 chapter on the role of music at the institution (Brooker 2005). In 2012, J. Sergio del Campo Olaso placed Schalkenbach's work on a par with that of more historically established organmakers (del Campo Olaso 2012).

In my 2015 self-published monograph, I examined Schalkenbach and his influence (Wilson 2015a). I argued that the Italian Futurists' Art of Noises (particularly their appearance at London's Coliseum music hall in June 1914), rather than being the birth of experimental music, actually represented the logical conclusion to a trend for music hall-based descriptive music that Schalkenbach's electromusical entertainments instigated. F. T. Marinetti, the Futurist mouthpiece, had championed the music hall - his 1913 'The Meaning of the Music Hall' essay cheered

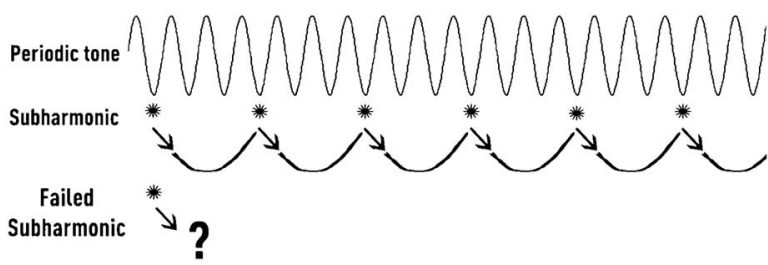

Figure 1. The subharmonic's (and failed subharmonic's) dynamical relationship to a periodic tone shown here as a recurring point of contact. Both subharmonics and failed subharmonics owe their existence to the fundamental periodic tone, but failed subharmonics constitute non-recurring blips. 'the variety theatre destroys all that is solemn, sacred, earnest, and pure in Art - with a big A' (Daily Mail 21 November 1913). When Marinetti, Luigi Russolo and Ugo Piatti presented the Art of Noises in 1913 and in London in 1914, they did so in a manner as to startle the audience in the spirit so familiar to music hall habitués.

Descriptive music was a genre where real-world sounds were imitated to convey a narrative. In artistic and musical circles, it was generally seen as permissible for a composer to musically describe a scene (Beethoven often did so, notably in his Wellington's Victory), but when taken to extremes it was seen as a vulgar negation of the composer's craft. Frantisek Kotzwara's (c.1740-91) popular c.1788 sonata Battle of Prague (for piano or harpsichord, cello, violin and an optional drum) came to define the style. This multimovement piece musically evoked war in clearly demarcated sections. Schalkenbach's act followed this descriptive fantasia model, but he sought to push the realism of the noises further. His use of technology to achieve these ends was not without precedent, as in the early 1800s, Johann Nepomuk Maelzel (1772-1838) devised a mechanical musical automata show: his 'Conflagration of Moscow' London exhibition featured 'Russian drums beating to arms, the roaring on cannon, and the clang of trumpets in all directions' among other musical automata (The Morning Post 13 July 1819). Nevertheless, Schalkenbach's electrical instrument was a strikingly original novelty for British music hall audiences when he made his debut in 1863.

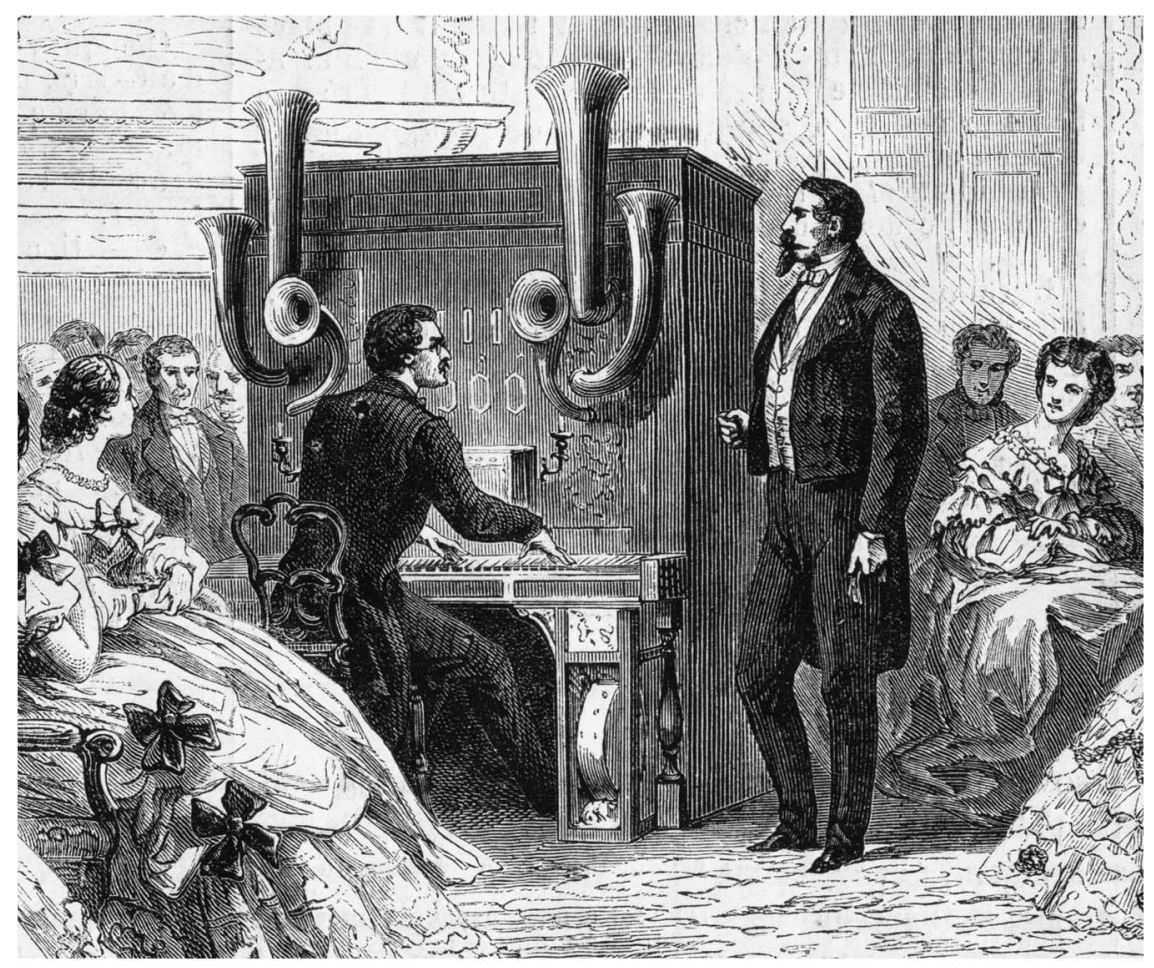

Figure 2. J. B. Schalkenbach performing at the Palace of St Cloud before the Empress and Emperor of France, 1862. 


\section{JOHANN BAPTIST SCHALKENBACH}

Johann Baptist Schalkenbach was born in Trier, Prussia in 1824. In the 1850s he was in business as a merchant of fabrics, clergy clothes and church cloths. He took the bold decision in 1861 to devise a patent for a new musical instrument where a performer could mechanically control a multitude of instruments and effects. When the patents were sealed in Europe (and the United States) in 1862, the French piano manufacturer Alexandre Bataille \& Co. was advertised as putting Schalkenbach's ambitious instrument into commercial production, calling it the 'Piano-Orchestre', but it did not catch on (Figure 3).

The instrument, as its patent describes, was a combination of a footbellow-based harmonium coupled with a smaller accordion-like 'harmoniflute' (an instrument associated with Constant Busson of Paris) and musical bells. Included were gongs, cymbals, a bass drum, snare drum and triangle all playable with the forearms or wrists via mechanical buttons, leaving the fingers free to play the keyboards. Each of the harmonium keys could also be locked down to sustain tones whilst playing elsewhere. By the use of tremolo valves in the throats of the funnels, a buzz could be imparted to the harmonium tones to simulate brass instruments. The patent also described the addition of castanets, cuckoo pipes and whistles, and a windmanipulated hollow ball capable of various sounds 'sometimes like the whistle of a locomotive, sometimes like the raging of the storm'.

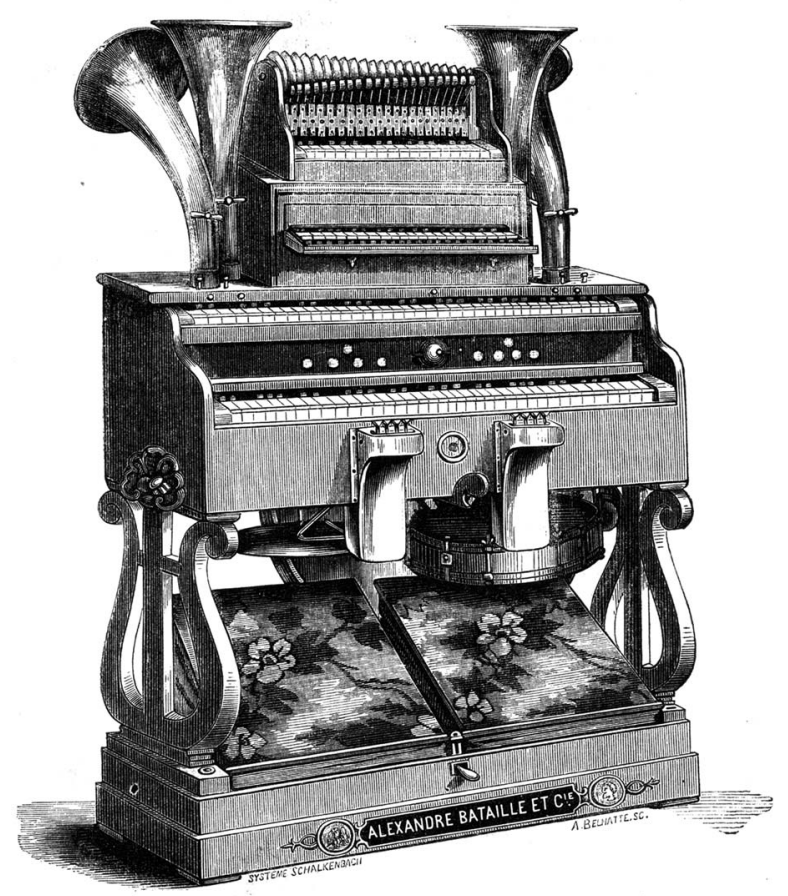

Figure 3. Early commercial version of Schalkenbach's nonelectrical Piano-Orchestre, marketed by Alexandre Bataille, 1862.
Schalkenbach's performance career began in 1862 when he performed upon his instrument before the Empress and Emperor of France at the Palace of St Cloud. Significantly, it was here that Schalkenbach renamed his instrument the 'Piano-Orchestre ÉlectroMoteur', introducing nine new buttons to activate electrical add-ons.

Schalkenbach's UK 'Piano-Orchestre' debut took place in June 1863 at Leicester Square's Royal Alhambra Palace. The venue's 'royal' appellation was merely derived from the premises' previous incarnation as the celebrated Royal Panopticon of Science \& Art; the Alhambra itself was rather more prosaic as an entertainment venue, catering for widely popular tastes. It appears that no electrical aspects were reported in Schalkenbach's act (although he was said to control twenty-six instruments), but in September a new engagement at the Oxford Music Hall (on Oxford Street) saw him billed playing the 'Orchestral Piano with electric action'.

In the spring of 1864, Schalkenbach relocated to the north of England, then in 1866 travelled to Scotland for performances in Glasgow. His instrument had a prominent battery, and buttons on the console activated objects placed all around the performance space, such as drums and pistols.

In December 1866, Schalkenbach returned to London to perform on his 'Piano Orchestra with Electric Motion' at the Royal Polytechnic Institution, where its director - John Henry Pepper (of Pepper's Ghost fame) - was popularising scientific demonstrations at the time, creating a theatre/lecture hall hybrid full of technically sophisticated visual and acoustic novelties (Weeden 2008). This was an ideal environment for Schalkenbach who himself traversed both 'high' and 'popular' cultures (an early example of his instrumentality in reconciling these divisions was his performance at Newcastle's Victoria Music Hall before the town's mayor, and also the mayor and mayoress of Gateshead, indicating the growing respectability of music halls) (Newcastle Daily Chronicle 2 January 1865).

Schalkenbach remained at the Polytechnic as resident organist for a little over three years, later performing on the institute's newly acquired Bryceson electric-action organ. During this time he refined his own instrument. He benefitted from his friendship with Hungarian mechanician and harmonium-builder Francis Seraphicus Pichler (c.1812-1900), at whose shop nearby the Polytechnic Schalkenbach was lodging. Pichler too was involved with the Polytechnichis trapeze automaton the Automatic Leotard was exhibited alongside Schalkenbach's instrument inside the Great Hall. Both Pichler and Schalkenbach married sisters from the Hayward family who had a background in glass artistry.

When Schalkenbach returned to the music hall circuit in 1871 (billed alongside blackface minstrels at 
St James's Hall in Piccadilly, London), he had retitled his instrument as the 'Orchestre Militaire Electro Moteur', evoking the Franco-Prussian war whilst also capitalising on a fashion for orchestras augmented by military bands (Herbert 2013). It boasted many upgrades, and every element was brought into play in Schalkenbach's military fantasias. An 1874 review gives an overview of the effects:

Seven separate electric currents, we are told, are under the control of the performer. Pressure upon one contact will instantly cause the drum to beat; pressure further on sends the current to the electros of the kettle drum, whilst a slight movement of hand or wrist brings cymbals and a big drum into play; another movement and there is the Chinese gong; again we have triangle, castanets, sledge-bells, military drums, church chimes, pistol shots, and cannons. Another contact, and in a moment even electricity travels to the roof of the building and also to the apparatus around the hall, and causes vibrations as if a thunderstorm were heard approaching from the distance; you hear the howling of the wind and the downfall of a torrent of rain. (Lloyd's Weekly Newspaper 15 February 1874)

The above description of the thunderstorm highlights that in the absence of any established listening paradigms for electrical music, observers could easily be misdirected to attribute electrical origins to acoustic sounds. Before the concept of electronic sound enabled electrically actuated sound to be distinguished from it, unknowing auditors often ascribed electrical origins to acoustic tones triggered by electric action. The storm effects were possibly triggered by a release mechanism - the rain sound was actually a cascade of buckshot, the thunder was a struck steel sheet, whilst the howling wind was a bellow-powered valve blowing upon a hollow copper ball. The effects are revealed in a US patent by Schalkenbach's only son, Nicholas 'Franz' Schalkenbach (1873-1929), who had emigrated with his wife to New York in 1925. He filed his patent for a 'Storm-Simulating Device' in 1927 but died two years later. He had no offspring to perpetuate the memory of his father's work.

Another example of the electrical/acoustic confusion is seen in an eccentric oratorial poem by John Carrington Sellars exalting chemical science to the status of Christianity. Chemistianity - first published in 1873 - contained a passage invoking Schalkenbach where Sellars referred to the role of chemistry in musical instruments: 'Producing voice-like or bird warbling notes/By hand or 'lectric force, as doth Herr Schalkenbach'. However, the second edition of Chemistianity (published a few months later) omitted Schalkenbach's name, instead reading: 'Producing voice-like or bird warbling notes/By means, it may be, of electricity'. Sellars was wise to be more circumspect, as Schalkenbach in fact achieved these "voice-like or bird warbling notes' with foot bellows, not electricity.
Evidently, Schalkenbach received many enquiries about his instrument, so in the summer of 1874 he took the unusual step of publishing notices in The Era and also The London \& Provincial Entr'acte stage newspapers offering his electrical expertise:

\section{MUSIC BY ELECTRICITY \\ HERR J. B. SCHALKENBACH}

Sole Inventor, Patentee, and only Performer on the Orchestre Militaire Electro Moteur, respectfully requests that all communications concerning Engagements, \&c., should be directed to his address at 162, Great Portland Street, Oxford-street.

In answer to many applications, Herr Schalkenbach is now ready to supply, or to give all necessary information for the construction of the various Electro-Musical Instruments and Appliances as used in his Entertainments during the last Fourteen Years, viz., Electric-String Instruments, Trumpets, Chimes, Bells, Cuckoo, Birds' Song, Drums, Triangles, Castenettes, Tambourines, Sledge Bells, Slash of Whips, Bagpipes, \&c. Instruments in direct communication with the keys of Piano, Harmonium, Organ; or, if desired, Musical Boxes with Electric Arrangement for Releasing the Flywheel. Imitation by Electricity of Thunder, Rain, Roaring of Waves, Lightning, Marching of Troops, Galloping of Horses, Locomotive in Motion, Electric Cannon, Mitrailleuse, Pistols, Rockets, Optical Music with Vacuum Tubes, \&c. \&c.

Instruction given in the use of all the above, be it for Solo Performance or in conjunction with the Orchestre.

For terms and further particulars apply as above. (The Era 31 May 1874; The London and Provincial Entr'acte 13 June 1874)

Advertisements for a new engagement in Liverpool announced that Schalkenbach's name was a 'household word' (The Liverpool Mercury 17 September 1874). But on 2 May 1875, St James's Hall (where he was installed) suffered a fire, destroying his instrument. There are conflicting reports of its value - one newspaper claimed that it was estimated by Schalkenbach to be worth the 'enormous sum of $£ 10,000$ ' (Prescot Reporter and St Helens General Advertiser 8 May 1875) but was only insured for $£ 900$, whilst another source more sensibly - reported that he estimated its value to be $£ 1,000$ (quoting the same insurance figure of $£ 900$ ) (The Liverpool Mercury 3 May 1875).

Since his arrival in the UK, Schalkenbach's work had won praise from the stage press. However, the fire prompted an unusually disparaging report in Concordia: A Weekly Journal of Music and the Sister Arts:

The Fates are hard upon Herr Schalkenbach, and have burned in the fire at St. James's Hall, Liverpool, his noiseproducing machine, the 'electric organ'. We are sorry for Herr Schalkenbach, because the 'divinity that shapes our ends' seems to share the human weakness of hitting the 
little people and letting big ones alone. There are other producers of hideous noises under the name of music whom it would have been much more meritorious to silence. But these are sharp practitioners who know how to humbug simple folk by fitting a fine theory to very poor practice, and getting the compound accepted as gospel. Herr Schalkenbach made a row and called it music, but he did not attempt to establish it as the highest development of art. Why then burn his 'electric organ'. (Concordia 22 May 1875: 1(4))

Concordia was a short-lived journal that focused on drama and musical high culture. It was not averse to modern concepts - it praised Frédéric Kastner's (1852-82) electric pyrophone trials (Kastner 1881), enthusing that 'we may soon find operatic ensembles strengthened by the mellow notes of the gaseliers round the boxes' (Concordia 15 April 1876: 2(51)); elsewhere, the journal ran a series of articles on Helmholtz's (1821-94) revolutionary acoustical teachings. The slight at Schalkenbach indicates the chasm between theatre and music hall culture remained significant. The alleged 'noisiness' of Schalkenbach's act likely referred as much to the percussive/explosive effects as to the buzzing valves that distorted the harmonium tones to mimic brass instruments. What was likely to offend more earnest music critics was Schalkenbach's combining of disparate musical elements: the Entr'acte wrote (playfully) that '[Schalkenbach] is no respecter of composers; he will play an excerpt from Beethoven's sonata pathetique one minute, and glide into [the popular ballad] 'Wait till the clouds roll by' the next' (The London and Provincial Entr'acte 9 March 1889). This would have been viewed as sacrilege by Concordia, which did not veil its contempt for concessions to popular culture, and indeed for the music hall (Concordia 2 October 1875: 1(23)). Such entrenched attitudes go some way in addressing the musings of the Entr'acte - a stage newspaper supportive of Schalkenbach - that questioned in 1883, 'it seems to us something more than strange that [Schalkenbach's] entertainment, which is infinite in its variety, should not be secured for some of our more important places of amusement, establishments where the demonstrator would be given more scope for developing his experiments than are to be obtained at our music-halls' (The London and Provincial Entr'acte 28 April 1883).

Seven months later Schalkenbach had assembled a new instrument - in a review of its first outing at the London Pavilion it was described as 'a sort of infernal machine, which, beneath the touch of its master, can emit the sweetest of sounds, the grandest of harmonies; but which also can deafen us with the roar of thunder, dazzle us by the flash of lightning, frighten us by the discharge of artillery, beat drums, clang cymbals, ring bells far remote, and produce a mimic downpour of rain' (The Era 14 November 1875). Nearly a quarter of a century later, Spectator assistant editor Charles Larcom Graves (1856-1944), writing a disparaging piece on 'Realistic Music' under his C. L. G. anonym, recalled Schalkenbach's apparatus at this period, claiming 'it was in reality only an American [harmonium] organ with electrical attachments by which he was enabled to reinforce the instrument with drums, cymbals, gongs, and blue lights placed all round the room' (Graves 1900).

There were two significant engagements for Schalkenbach in the latter half of the 1870s: the Crystal Palace performances and, prior to this, his billing with celebrated stage magicians J. N. Maskelyne (1839-1917) and George Alfred Cooke (1825-1905) at Piccadilly's Egyptian Hall (from December 1876 to March 1877). Schalkenbach's absence from the stage for eight months prior to his Egyptian Hall appearance is highly suggestive of his involvement behind the scenes with Maskelyne and Cooke's 'Spirit Musical Box', appearing in August 1876 playing music on command, and the 'Mystic and Oracular Tambourine' placed within the audience space 'spirit rapping' answers to questions - these tricks can be discerned within Schalkenbach's 1874 notice above. Suggestion of electricity was of course withheld for magical effect.

At the Egyptian Hall, Schalkenbach did not entirely play down the electrical principles behind his own instrument, but a little misdirection was employed: he 'manages to puzzle the audience as to the extent and whereabouts of the effective band' (The Times 27 December 1876). This was a period where electrical tricks remained credible as magic entertainment, and the mysterious electrical aesthetic - for a short time - could happily co-exist alongside Maskelyne's spiritualism-debunking mechanism-orientated illusions.

Interestingly, in 1879 Maskelyne and Cooke unveiled their carbon-copy of the Orchestre Militaire Electro Moteur titled the 'Electric and Automatic Orchestraphone' played by in-house musician Charles Mellon aka Lawrence John Holder (1850-97) mimicking Schalkenbach's descriptive musical repertoire. Maskelyne and Cooke's first instrument was advertised for sale from December 1880 to April 1881 to allow a larger version to be constructed (Figure 4). In the mid-1880s it was renamed to occlude its electrical principles: 'Maskelyne's Mechanical and Automatic Orchestra'. From 1890 onwards it was manned by François Cramer (1850-1930).

In the 1880 s, the proliferation of electrical technologies - both in the second-hand trade and from the growing industry of electrical retail - led to an array of Schalkenbach-style acts. This rapidly negated electrical magic, and Schalkenbach's own expositions undoubtedly hastened its obsolescence: his act reached the pinnacle of electrical overtness in the 1880s when he began rigging electrical contacts on seats to administer electrical shocks - 'playing' the audience 


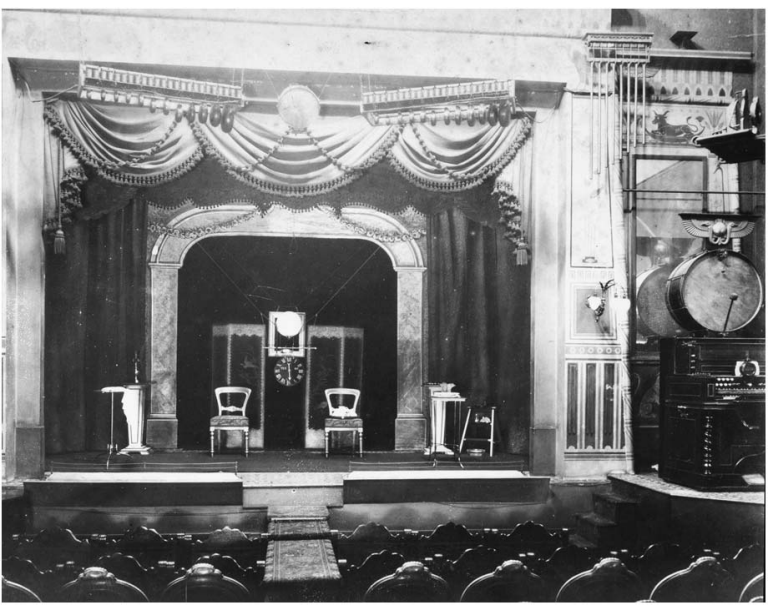

Figure 4. The last incarnation of the Maskelyne \& Cooke Automatic Orchestra (right) with electric tubular bells, gong, triangle, etc., and rows of bells and a drum suspended on the proscenium arch above the Egyptian Hall's stage (c.1900). Credit: Magic Circle Archive.

from his instrument. By 1911, Maskelyne's son Nevil Maskelyne (1863-1924) opined 'we cannot now, hang up a drum with electrical tappers concealed inside it, and expect an audience to be mystified by hearing that drum played invisibly. The day for that sort of thing has gone by, never to return' (Maskelyne and Devant 1911) (yet time-honoured quirks of generational heterogenesis annulled this statement by the late twentieth century at the onset of a still-vibrant artistic phase of electromechanically orientated electroacoustic musical intrigue!).

With the growth of the railway infrastructure, railway transport - as well as being drawn upon as a thematic motif by Schalkenbach - opened up opportunities to convey weighty electromusical apparatuses much further afield (Figure 5). Schalkenbach's 1874 expertise-offering adverts marked the beginning of a slew of near-identical electromusical acts such as Herr Renier aka Charles William Holcroft (1858-?), appearing in 1887, and Italian engineer/performer Carlo Bozza (c.1856-?), who, according to the journal Iron (previously The Mechanics' Magazine), had also 'invented a new musical instrument, playable only by electricity; it is made of porcelain, and from it he produces excellent music' (Iron 4 May 1888: 31(799)).

The earliest adopter of Schalkenbach's act was 'Professor' Beaumont aka 'The Royal Necromancer', a Yorkshire-born ex-bicycle shop owner who unveiled it in London in February 1874 - a catalyst for Schalkenbach's advert (Lee 1874). Beaumont later travelled to Ireland, Guernsey and the Isle of Wight with his apparatus. He also advertised cinematographic projections as early as 1902 (Beaumont 1975).

In October 1883, Schalkenbach was installed at the Queen's Palace of Varieties in Poplar. Two years later,

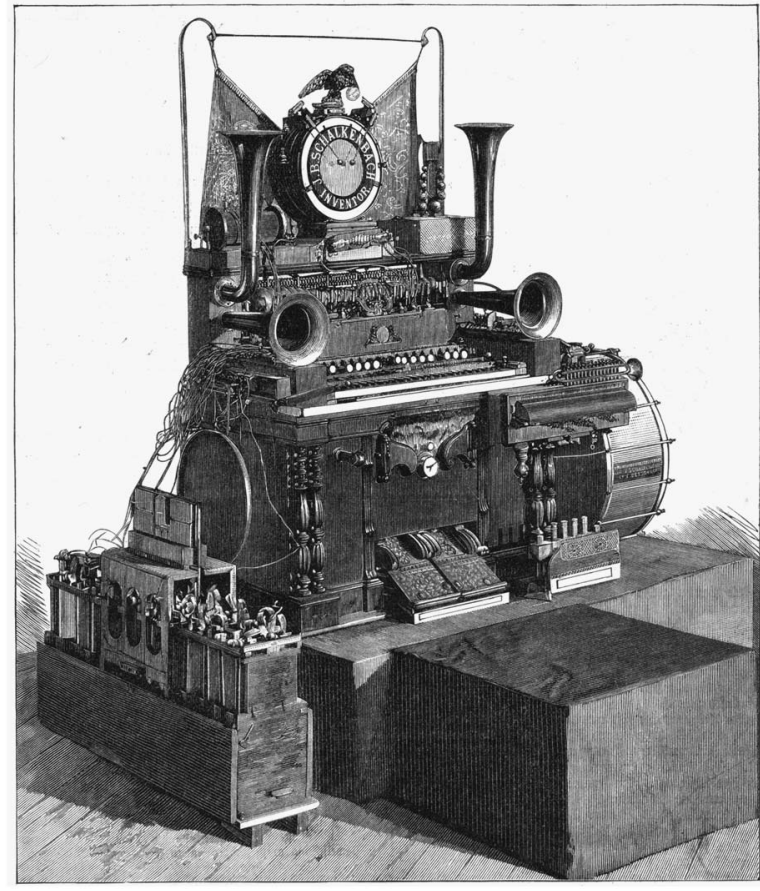

Figure 5. Schalkenbach's Piano-Orchestre Electro-Moteur, 1893.

the hall's bandmaster Peter James Conroy (1853-1930) introduced his suspiciously familiar 'patent orchestrephone' which he expanded with electrical effects (The Era 2 April 1887). It was spuriously stated to be patented, and reported to be 'his own invention' (Portsmouth Evening News 23 September 1890). As well as playing the instrument, Conroy would conduct an actual band.

The Queen's Palace 1883 engagement also led two unlikely co-performers on the same bill to shamelessly pirate Schalkenbach's entertainment: skater, comic singer, impressionist and noted plagiarist (The London and Provincial Entr'acte 25 January 1873) H. F. Juleene, whose real name was John Parsons (1841-1905), together with singer, pianist and male-impersonator Dot D’Alcorn aka Susette D'Alcorn (1859-1903) formed an entertainment duo called Mephisto a year later in Birmingham, in September 1884. They later married. Ironically for a performer adopting an exotic nomde-plume, Juleene's advert boasted that Mephisto was 'not indebted to any foreign instructor. Every foreign importation is improved upon in the hand of Old John Bull' (The Era 11 October 1884). D'Alcorn hailed as 'the one and only lady electrician in the world' in adverts - dressed as the titular demon and performed at the organ console. Derivative as Mephisto was, it did obtain originality from D'Alcorn's role as the first professional female 'electric musician'. They had no children, and Susette D'Alcorn's name is misspelt as 'Lusette' on their headstone in Wandsworth Cemetery (Wilson 2015a). 


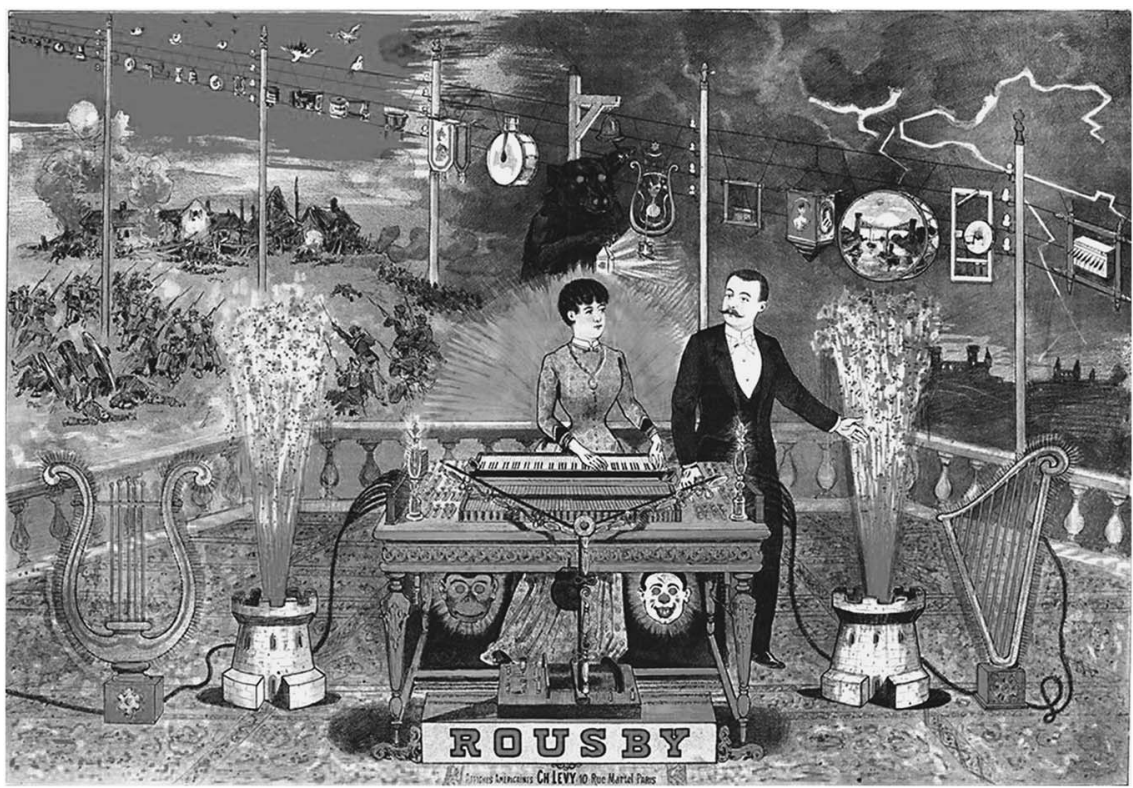

Figure 6. Maud Irving and Edwin Rousby's electro-musical entertainment c.1895.

Other copycats included Hungarian performer Sandor Rosner aka Edwin Rousby (1856-1927) and his wife Lily aka Maud Irving (c.1855?-?) (Guadaño 2014). Like Professor Beaumont, Edwin Rousby became interested in cinematography at the turn of the century. When Rousby and Irving reached the UK in July 1895 , they had formed a duo strongly resembling Juleene and D'Alcorn's Mephisto (Figure 6), as Maud Irving was by this time the focal point of the act, playing the electromusical console. The similarity of the Rousbys' act did not go unnoticed by Juleene, who, with his exaggerated delusions of priority, blustered rudely nationalistic braggadocio in a Mephisto advert: 'H. F. Juleene, scientific and practical electrician, twenty years before the Hungarian refugees landed in my country' (The London and Provincial Entr'acte 14 September 1895).

In Rousby's '20th century creation' simply titled 'Electricity' - shown in Blackpool in 1900 - he upturned the performer-audience dynamic so that 'every visitor will be a performer. All that is required is to press buttons, turn handles, pull levers, and at once you will be able to produce the most marvellous electrical effects' (The Era 8 September 1890). Such a radical role reversal signalled the death knell of electrically actuated music as a stage entertainment (Walker and Walker 1925).

\subsection{Electric music's decline}

Nineteenth-century Schalkenbach copycats were defined by an aversion to having their affairs managed by the nascent variety agencies (customarily taking 20 per cent of a performer's earnings). Schalkenbach signed up with various variety agents for short periods, including H. W. Wieland, (c.1848-1922), Charles Roberts (1839-97) and George Manning (c.1845-?), but had no consistent figure championing his work, unlike Maskelyne and Cooke whose names are still remembered today owing to the support of their long-standing patron and manager, William Morton (1838-1938) (Morton 1934). Yet this does not fully account for electromusical exponents' obscurity today.

Electric lightbulbs can be instantly turned on and off at will; this was a novelty unachievable with traditional gaslight. Electromusical entertainments relied heavily on integrated electrical lighting tricks to reinforce the spectacle, and therefore the introduction of venues' own in-house electric lighting detracted from the electromusical spectacle. Electric light became more commonplace in public venues from the 1880s onwards, popularised by exhibitions such as South Kensingon's 1885 International Inventions Exhibition, and the Crystal Palace 1892 Electrical Exhibition.

Electromusical culture was also inextricably tied to descriptive music, and the aversion to this kind of music among early twentieth-century musicologist tastemakers such as Percy Scholes also added a further impediment to electric music becoming reconciled into later discourses on alliances between music and electricity. Scholes's 1938 Oxford Companion to Music stated that these "cruder kinds of "programme music", enjoyed 'temporary popularity in uncultured circles' (Scholes 1938). His tome was not necessarily viewed as gospel, although he did declare that it was longer than the Bible (Scholes 1969). Even Luigi Russolo, in 1914, sought to distance his Futurist Art of Noises from the descriptive tradition (but his words had little effect on critics ('Autolycus' 1914)): 'My noise spirals [noise compositions] are not mere impressionist reproductions 
of the surrounding life, but synthetically-treated noise emotions' (Russolo 1914).

Another factor contributing to the present obscurity of electromusical culture is the entertainers' tradition of avoiding divulging too much information in order to guard against plagiarism (as seen with the secrecy surrounding the Punch and Judy 'swazzle' for distorting the performer's voice (Speaight 1990)) - this meant that the exact electrical workings of a performer's electromusical apparatus was never made public. This hampered any osmosis into popular scientific discourse, as illustrated when, in the twilight of Schalkenbach's career, the Electrical Engineer journal quipped during a digression within a book review: 'That reminds one of another electrical incident about which people would like to know more. Was it telephonically or phonographically that Herr J. B. Schalkenbach transmitted sounds to a distance' (The Electrical Engineer 24 January 1890). It is unlikely that Schalkenbach employed either technique.

In the early twentieth century, Schalkenbachian flourishes were requisitioned and co-opted into automatic orchestral fun-fair novelties, cinema organs and theatrical 'noises-off' sound effects for dramatic productions.

\section{EARLIEST ELECTRONIC MUSIC DEMONSTRATION}

The magician Will Goldston (1878-1948) wrote in 1912, 'original work, carried out in detail, would be appreciated in a laboratory, but would be wasted in a theatre. The public want to be startled, and it is necessary to startle them' (Burrows and Goldston 1912). Indeed, this capacity to startle was the life-sustaining currency of electromusical acts. Electronic music on the other hand was much more delicate, and - being 'original work' lent itself to the laboratory rather than the theatre. The first public demonstration of electronic sound in Britain took place on 31 December 1895. This too is a failed history; it is not mentioned in any electronic music histories.

The electronic apparatus was devised by Alfred Graham (c.1857-1929) whose firm produced telephonic apparatus and early loudspeakers. It was demonstrated in the second of six Royal Institution Christmas lectures on 'Sound, Hearing and Speech' given by John Gray McKendrick (1841-1926), a physiologist who - as technologies availed themselves was able to indulge his passion for experimental acoustics in the 1890s (McKendrick 1919). The Royal Institution was a more intimate venue than the music hall. The device showcased there consisted of a switch, a battery and a carbon granule microphone and loudspeaker horn placed close enough together to produce audible brass-like self-oscillating feedback tones. McKendrick pointed out that it contained 'the germs of a possible musical electrical instrument,

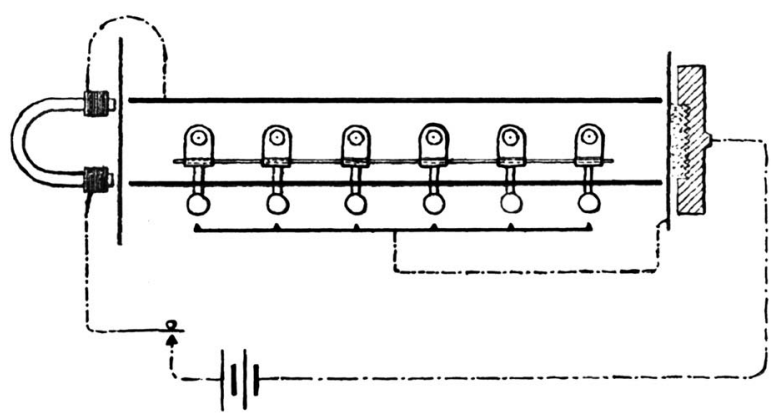

Figure 7. One possible configuration suggested in Alfred Graham's 1894 patent 'A New or Improved Method and Means of Producing Sound' - an early electronic instrument employing feedback: 'For musical purposes I may place a tube such as that of an ordinary flute between the two diaphragms and adjust the note by varying the holes in the tube [...] A key or circuit closer is inserted in the battery circuit.'

which might be made entirely independent of any of the mechanical methods ordinarily applicable to the musical instruments at present known to the world' (The London Standard 1 January 1896).

Over the course of his lectures, McKendrick presented a thorough review of the progress of acoustical science. He championed Graham's innovations, another of which was an electrically amplified phonograph, on which McKendrick insightfully mused 'I feel sure that it is in this direction that further developments may be expected from the phonograph' (McKendrick 1897). As a further example of McKendrick's farsightedness, in his writings on speech he envisaged a machine whereby individual segmented phonograph traces of spoken syllables might be composited as in typesetting; strung together to create sentences of artificial speech (McKendrick 1896a).

In 1896 McKendrick mused in a short paper on Graham's 'Electrical Musical Tones' that an 'electric flute' could be produced by placing a perforated tube between the microphone and horn (McKendrick 1896b). This was in fact a suggestion given by Graham himself in his 1894 patent for the technique (Figure 7).

Graham specified that 'the pitch, loudness, or quality of the sound produced may be varied by varying the battery current in strength or changing its direction or by changing the forms of the trumpets [horns] or varying the relative positions of the instruments [i.e. the horn and microphone]' (Graham 1894). The electrically variable 'quality of sound' reminds us that electronic music entailed a then-insurmountable paradigm shift in musical consciousness; partaking in its creation demanded an advanced sense of tonal awareness, the foundations for which had been laid by Helmholtz decades earlier (and whose influence upon music itself has yet to be fully appraised). McKendrick (who authored a biography on Helmholtz in 1899) had articulated in 1873 how, prior to Helmholtz's 
discoveries with pitched resonators, 'we were unaware of the existence of harmonics'; 'we were not conscious of them'; there was an awareness of timbre distinctions between instruments, but before Helmholtz a musical note was experienced as a 'whole' (McKendrick 1873). An odd fin de siècle tract authored by erudite melancholiac 'Stephen Allard' despaired at the plight of the idealistic musical aesthete in the midst of such ructions within musical thought. His writings serve to illustrate a characteristic resistance to the ingress of science into music:

And your musical eclectic, your doubting, rest-seeking musical Erasmus must creep into a corner out of the way of strife, there to discover to his sorrow that in his new religion there is ever but a grain of the charming vague to an ounce of the unlovely mathematical, and that he cannot have the grains apart from the ounces in which they are mingled. (Smith 1894)

In a musical culture too unripe for electronic instruments, Alfred Graham did not pursue his electronic sound-making technique. Even the ostensibly forwardthinking McKendrick had lamented - in view of the perceptual revelations afforded by the phonograph that it is rather a pity to say that even [musical] expression is mechanical' (McKendrick 1897). As McKendrick approached retirement, Graham pursued more profitable endeavours in meeting the demands of industry - namely in perfecting the reproduction of sound by horn and loudspeaker. Graham's son also ran the firm, which later produced the Amplion loudspeaker in the 1920s - giving electronic music a mouth.

\section{THE OSCILLATION OUTRAGES}

The BBC started public broadcasting in 1922, kickstarting the wireless radio industry. Radio sets were first listened to with headphones, but in the mid-1920s the introduction of loudspeakers (such as the Amplion) on valve sets compelled listeners to increase volume. A quirk of early valve radios meant that increasing volume beyond a certain threshold created an electronic feedback frequency that would energise the aerial, and the oscillation interference would be reproduced in other radio sets tuned to the same frequency in the locality.

The heterodyning principle of combining two radio frequencies to produce an audible difference tone was employed in Léon Theremin's (1896-1993) instrument. When Theremin presented it in London in December 1927, Professor A. M. Low (1888-1956) reportedly said of Theremin that he 'makes a wireless set oscillate', not entirely in a disparaging spirit, but to imply that the phenomena was by no means new (Dundee Courier 13 December 1927). However, Theremin had consolidated the two heterodyne frequency sources within his instrument - the self-contained radio frequencies did not cause interference. Radio oscillation - or 'howling' - was created by a home radio's own radio oscillation feedback frequency heterodyning against an actual broadcast radio station's carrier wave. Prevalent at the time was an inconsiderate method of tuning in to a radio station: the radio's volume would be pushed into self-oscillation, which would remain inaudible until a radio station frequency was approached. The vicinity of the broadcast wavelength would be heralded by a high-pitched tone that lowered as the wavelength was reached, and at the lowest point the volume dial would be ducked in order to hear the broadcast. Many people tuning radios in this way meant that these wild electronic tones locally intruded upon radio broadcasts.

Whereas music's descriptive noise effects attracted contempt (particularly from musicologists), oscillation was more blatantly an affront to music: it was a new anomalous noise requiring no special skill, and often ruined musical broadcasts. On the subject of descriptive effects, it is worth noting that when poor radio reception was acoustically spoofed for an 'Uncle Edgar' broadcast (Percy Edgar 1884-1972) on Birmingham's BBC station in 1924, the sounds comprised 'lead shot on a kettle-drum, paper rustled before the microphone, the breaking of matchwood, and an oscillating valve' (The Hull Daily Mail 25 January 1924): an example of oscillation falling within the descriptive effect catchall - a sound descriptive of itself.

BBC chief engineer P. P. Eckersley (1892-1963) spearheaded anti-oscillation propaganda and psychological deterrents, framing oscillation as a moral failing (Figure 8). The nature of oscillation meant that it was difficult to locate offenders, and anti-oscillation initiatives led to a period of oscillation-angst culminating in the late 1920s with the General Post Office's unveiling of the spurious 'detector vans' to supposedly pinpoint offenders (which were actually only psychological deterrents) (Eckersley 1941). Oscillation's

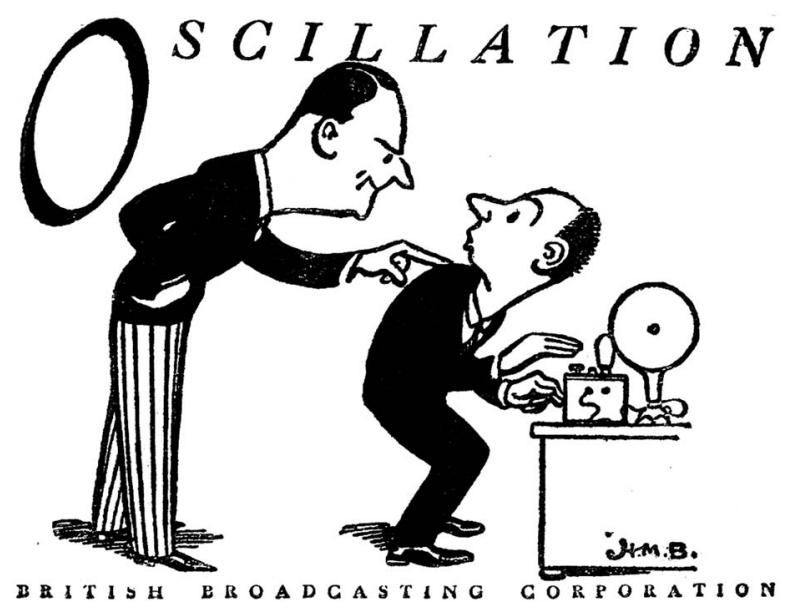

Figure 8. The cover of the BBC's 'Oscillation' pamphlet, 1927, comically illustrated by H. M. Bateman to offset its dictatorial tone. 
'radio-as-transmitter' concept caused confusion: in 1928 a lady apologised to the BBC for talking whilst her radio was on, believing that the radio set was sensitive enough to rebroadcast the sounds in her home back to the live studio broadcasters (MacGregor 1928).

Most oscillation occurred through ignorance, but Eckersley identified deliberate oscillation too (Eckersley 1924). Correspondence in local newspapers revealed instances of gratuitous oscillation such as beating in time with music and, notably, in 1925, a broadcast religious sermon where the 'air was full of oscillators' warring to 'chase one another off the ether' (a possible manifestation of the tit-for-tat revenge oscillation - the 'howl for a squeak terror'), and most extraordinarily, in 1930, 'three or four' oscillating 'fanatics' apparently orchestrated their interference over a vaudeville broadcast - 'there is no doubt these pests had an arranged plan' (Wilson 2015b). Other listeners wouldn't necessarily hear the same pitch as the oscillation tone in the oscillating radio, so remotely 'harmonising' pitches of multiple oscillating radios was impracticable: the result would have been arbitrary discord for other listeners.

Today we may reconsider deliberate oscillation as a rustic form of electronic sound intervention performed by roguish anonymous experimenters. At the time, however, it was seen as a disgraceful habit, and a bane to all honest listeners who had paid their licence fees (and thus, oscillation was linked to licence fee evasion). Oscillation declined during the 1930s when superior circuits, higher powered radio transmitters and directional aerials obviated the issue.

\section{CONCLUSION}

Both Schalkenbach and the phenomenon of oscillation were in the public consciousness in their respective heydays - but their failure to be absorbed into electronic music historical studies is the result of a concentrated de-emphasis by influential writers in the field of music who were more often than not musicians themselves, or at least, in the case of George Bernard Shaw for instance, had high-minded ideas on the function and performance of music. With oscillation, the negation went beyond mere de-emphasis, and formed explicit condemnation from many angles, thus the phenomenon and associated cogitation upon it was stamped out. Theremin himself took pains to excise the semblance of radio oscillation from his instrument by cultivating a musicianly virtuosity, presenting the instrument as a legitimate addition to the orchestra, performing pieces by Schubert, Offenbach, Camille Saint-Saëns and Scriabin.

The complete absence of Alfred Graham's groundbreaking electronic instrument from historical discussion is more curious, but can nevertheless be explained by returning to the failed subharmonic analogy - in this instance it failed to resonate into historical continua from the very outset. But when, at a later stage, culture has sufficiently adapted, an echo of the original failed history may find resonance. For example, on 8 December 2014, radio artists Knut Aufermann, Sarah Washington and myself organised an evening of live feedback music to mark the 120th anniversary of Graham's original patent for the instrument. A facsimile of the patent formed the hand-out. The evening prompted many enthusiastic enquiries from audience members: 'why don't I know about this?' It is seen, however, that in this resurgence of interest, the essence of the original singular historic event is not suddenly recuperated into a 'successful history', but it is rather a reframed echo: the aforementioned interest in Graham's instrument took place during an evening of feedback-based electroacoustic music tinged with 'noise-music' aesthetics - a culture completely alien to the failed history's original players in the 1890s.

In this article it was important to establish for each 'failed history' detailed, linear narratives to preserve their original essence and factuality as far as possible. But their appearance here unavoidably colours them as obscure archaeological curios under the Alternative Histories of Electronic Music banner. Yet this slight recolouring of these historical events is the key to affording them a wider recognition. Italian Futurism, for instance, might today constitute a failed history were it not for it adapting itself to fascism, and later, when its fascist association became unpalatable in the post-war period, its recuperation by historians redefining it in terms of modernism - accentuating its technological, materialist thrust. More recently, researcher Luciano Chessa made close study of primary source material to reassert the hitherto obscured esoteric grounding of Luigi Russolo's Futurist art, especially his Art of Noises (Chessa 2012). The failed subharmonic analogy is illuminated further by one British critic in 1914 who, commenting on Russolo's Art of Noises, hinted at qualities of unresponsive resonance within cultural systems: 'those Futurists who find matter for idealism in "poverty, hunger and dirt" [from Thomas Hood's 1843 poem The Song of the Shirt evoking sounds of arduous toil] should be made to save their symphonies for the future when, it is to be hoped, changed conditions will at least lend to their art an archaeological interest' (Birmingham Daily Gazette 19 January 1914). Use of Robert Schumacher's term 'failed subharmonic' as an analogy may be justified by bearing in mind that recorded history itself, like electronic sound, is merely an artificial representation of actual real-world happenings.

\section{REFERENCES}

'Autolycus' [Grace, H.] 1914. Unconsidered Trifles. Musical Opinion. July. 816-18. 
Beaumont, C. W. 1975. Bookseller at the Ballet: Memoirs, 1891 to 1929. London: Self-published.

Brooker, J. 2005. Paganini's Ghost: Musical Resources of the Royal Polytechnic Institution. In R. Crangle, M. Heard and I. van Dooren (eds.) Realms of Light. Ripon: Magic Lantern Society.

Burrows, J. F. and Goldston, W. 1912. Secrets of Stage Hypnotism, Stage Electricity, and Bloodless Surgery. London: Routledge.

del Campo Olaso, J. S. 2012. La electricidad aplicada al órgano y la aportación de Aquilino Amezua. Musiker 19: 15-174.

Chessa, L. 2012. Luigi Russolo, Futurist: Noise, Visual Arts and the Occult. Berkeley: University of California Press.

Eckersley, P. P. 1924. Captain Eckersley Explains. London: Wireless Press.

Eckersley, P. P. 1941. The Power Behind the Microphone. London: Jonathan Cape.

Gaines, J. R. (ed.) 1981. The Lives of the Piano. New York: Holt, Rinehart \& Winston.

Graham, A. 1894. A New or Improved Method and Means of Producing Sound. GB patent \#290 1894.

Graves, C. L. 1900. Realistic Music. The Spectator, 17 February. 241-2.

Guadaño, L. 2014. Edwin Rousby: Un Misterio Desvelado. Filmhistoria online. www.raco.cat/index.php/Filmhistoria Online/article/view/286790 (accessed 11 October 2015).

Herbert, T. 2013. Music \& the British Military in the Long Nineteenth Century. Oxford: Oxford University Press.

Jenness, G. A. 1967. Maskelyne and Cooke, Egyptian Hall, London, 1873-1904. Enfield: Self-published.

Kastner, F. 1881. Electricity Applied to the Pyrophone of Mr. Frederic Kastner. Paris: Palais des Champs-Elyseés.

Lee, W. H. 1874. Hague's Minstrel and Dramatic Journal Supplement (September). Liverpool.

MacGregor, J. C. S. 1928. The Lighter Side of Broadcasting. The Southern Reporter (Special Broadcast Issue) 31 May: 7.

Maskelyne, N. and Devant, D. 1911. Our Magic. London: Routledge.

McKendrick, J. G. 1873. On the Necessary Conditions of Sensations as Illustrated by the Sense of Hearing. Edinburgh.
McKendrick, J. G. 1896a. On the Tone and Curves of the Phonograph. The Journal of Anatomy and Physiology 29: 583-92.

McKendrick, J. G. 1896b. Note on Mr. Alfred Graham's Method of Producing Sound by an Electrical Arrangement. Proceedings of the Philosophical Society of Glasgow 28: $46-8$.

McKendrick, J. G. 1897. Sound and Speech Waves as Revealed by the Phonograph. Proceedings of the Philosophical Society of Glasgow 28: 201-35.

McKendrick, J. G. 1919. The Story of My Life. Aberdeen: Self-published.

Morton, W. 1934. 'I Remember': A Feat of Memory. Hull: Goddard, Walker \& Brown.

Russolo, L. 1914. Futurism and the Art of Noises. (No publisher stated).

Scholes, P. A. 1938. The Oxford Companion to Music. Oxford: Oxford University Press.

Scholes, P. A. 1969. The Oxford Companion to Music. Oxford: Oxford University Press.

Schumacher, R. T. 1991. Aperiodicities in Musical Instrument Sounds. Pixel 2(1): 24-7.

Smith, G. (ed.) 1894. The Melancholy of Stephen Allard. London: Macmillan.

Speaight, G. 1990. The History of the English Puppet Theatre. London: Hale.

Walker, H. and Walker, A. H. 1925. Secrets of Modern Conjuring. London: Routledge.

Weeden, B. 2008. The Education of the Eye. Cambridge: Granta Editions.

Weldon, C. 1908. A Reminiscence of Music Hall and Variety Entertainments, Manchester, 1864-5-6. Leeds: Charles Weldon.

Wilson, D. 2013. 'Electric Music' on the Victorian Stage: The Forgotten Work of J. B. Schalkenbach. Leonardo Music Journal 23: 79-85.

Wilson, D. 2015a. The Magnetic Music of the Spiritual World: Electricity and Sound on the Victorian Stage. Bishop's Stortford: Self-published.

Wilson, D. 2015b. Rogue Oscillators. Fortean Times May: 38-44. 